\title{
The Characteristics and the Present Situations of Japanese Couples in Child-Rearing Period
}

\author{
Moe Onojima \\ International University of Health and Welfare Graduate School, Tokyo, Japan \\ Email: m0e.0n0jima@gmail.com
}

Received 25 June 2015; accepted 8 August 2015; published 11 August 2015

Copyright (C) 2015 by author and Scientific Research Publishing Inc.

This work is licensed under the Creative Commons Attribution International License (CC BY).

http://creativecommons.org/licenses/by/4.0/

c) (i) Open Access

\begin{abstract}
This study aims to find the characteristics of Japanese couples in child-rearing period through surveying Japanese studies of the couples and to discuss the present situation and the future of them in Japan in terms of psychological viewpoint. 115 studies which are found from the Japanese database of CiNii and Ichu-shi are classified into 4 main themes: 1) the role, 2) husband's support, 3) marital relationship, and 4) child-rearing stress and child-rearing anxiety. Results show 1) wife mainly carries parental role and though husband wants to participate in child-rearing, he can't because of working time, 2) mental support from husband and couple's communication reduce child-rearing stress, 3) wife's satisfaction with marital relationship dramatically decreases in child-rearing period, and 4) how to feel child-rearing stress depends on working styles. The facts that wife's satisfaction of marital relationship dramatically decreases in the child-rearing period and that wife mainly carries child-rearing work are common characteristics of the child-rearing period. On the other hands, little time of husband's participation in child-rearing is remarkable characteristic of Japan. From this characteristic, the problem that Japanese social support for couples in child-rearing period isn't enough can be pointed out. In Japanese current situation, couples need to have time to communicate and to share the idea of child-rearing to maintain good marital relationship in child-rearing period.
\end{abstract}

\section{Keywords}

Couples, Child-Rearing Period, Marital Relationship

\section{Introduction}

The birth of a child brings big changes to the marital relationship. This study defines the period when the child 
birth and the couple care their children for their healthy developments as child-rearing period. In child-rearing period, wife's satisfaction with marital relationship dramatically decreases (Kuramochi et al., 2007; Ito et al., 1998). So it can be said that the child-rearing period is the first period that couple confronts crisis of the relationship.

When a child gets birth, both husband and wife become parents and are added another task which is called childrearing. It is said that in Japan, there is traditional value of sex role division of labor; a value that husband is breadwinner and wife does all of household works (Nakagama et al., 2008). According to this value, most of studies of child-rearing period focus on wives.

Wives in child-rearing period have lots of problems: a burden of child-rearing itself, child-rearing anxiety, worrying about children's future (Aramaki et al., 2008), balancing between self-fulfilling and maternal role (Niwano, 2008), and so on. Child-rearing stress and child-rearing anxiety from those problems causes childrearing neurosis and impulsive feeling or behavior which become risks of child abuse (Matsumura, 2008). These days in Japan the number of child abuse increases (Cabinet Office, 2010) and emergent countermeasures are needed. There are some support programs for child-rearing from the government but those aren't enough. Social support decreases child-rearing stress and anxiety. In Japan, wife's social supports are mainly husband and her mother (Motoyasu et al., 2002; Tanaka, 2010). Although wives in child-rearing period have lots of problems, work-life balance is added as a new problem recently (Sato, 2013). This is the problem how to balance time and energy between work and family. This presents women's life style not only as mothers but also as individuals become thought to be important. These days in Japan, an environment for double-earner couple isn't supportive enough and the issue of children on waiting lists for nursery schools arises since the number of nursery schools isn't enough. Couples can't leave their children at nursery school and go for work both husband and wife, so in most case wife has to give up working. The problem of work life balance expresses both aspects women's successes in the society and that most wives have to give up their successes in the society.

Number of studies which focus on husbands is much smaller than those which focus on wives. But recently the effect of husband support becomes paid attention and the number of husbands' studies has accumulated. We need more husbands' studies in the child-rearing period.

In the child-rearing period, couples have various problems such as crisis of the relationship. Wives confront many problems: infant-care neurosis, child abuse, work-life balance, and so on. Husbands are needed to participate in child-rearing though they have to work hard. This study looks for characteristics of couple in the childrearing period through surveying Japanese studies of them.

\section{Method}

This study uses CiNii and Ichu-shi, the databases of Japanese studies, to search the papers. I looked through them in January, 2015 and it took a month to see all studies. Key words are "child-rearing period, couples", "child-rearing anxiety, couples" and "child-rearing stress, couples". There were 112 studies from CiNii and 128 studies from Ichu-shi. Studies which are posters, minutes of meetings, abstracts, and studies which couldn't access or don't aim at the period are excluded. Studies are limited to the original papers in Japanese or in English. 48 studies from CiNii and 53 studies from Ichu-shi are excluded and some studies were duplicated. Finally, 115 studies are surveyed (Figure 1).

\section{Result}

The studies are classified into 4 main themes; "the role", "husband's support", "marital relationship", and "child-rearing stress and anxiety". 8 studies which is about parental role or value of sex role division of labor are classified to "the role", 17 studies which examined the effect of husband's support or child-rearing behavior are classified to "husband's support", 24 studies which are about marital relationship are classified to "marital relationship", and 44 studies which attribute to child-rearing stress or anxiety of husband, wife, or both of them are classified to "child-rearing stress and anxiety". 16 studies which couldn't clarify into the 4 themes and 6 studies which are prospects articles are classified to "Others" (Figure 2).

1) The role

When child-rearing work is added, couple becomes parents and they have to play parental role. The recognition of the amount of carrying a parental role is different between wife and husband. Both quantitative and qualitative studies revealed difference between wife who has child in her belly from the pregnant period and husband who 


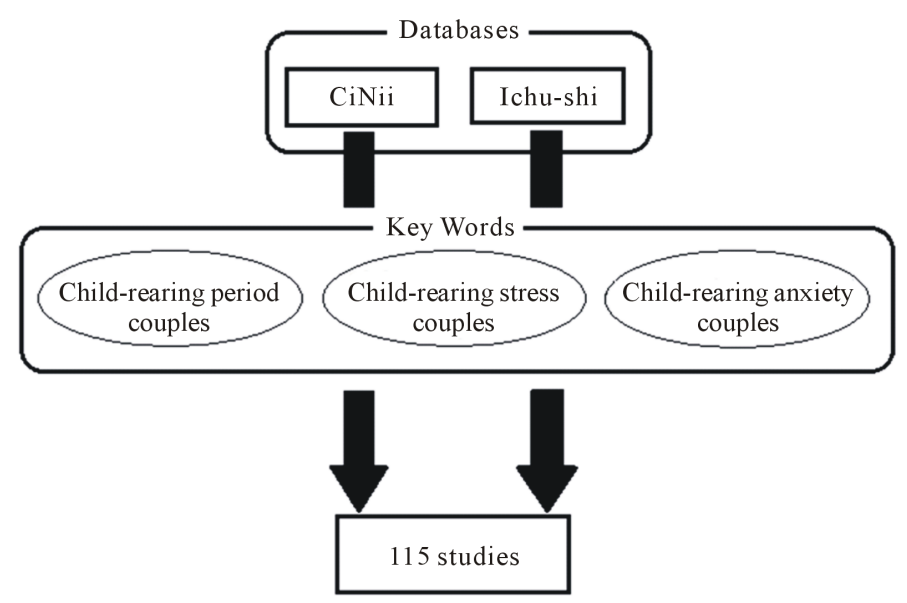

Figure 1. The process of survey.

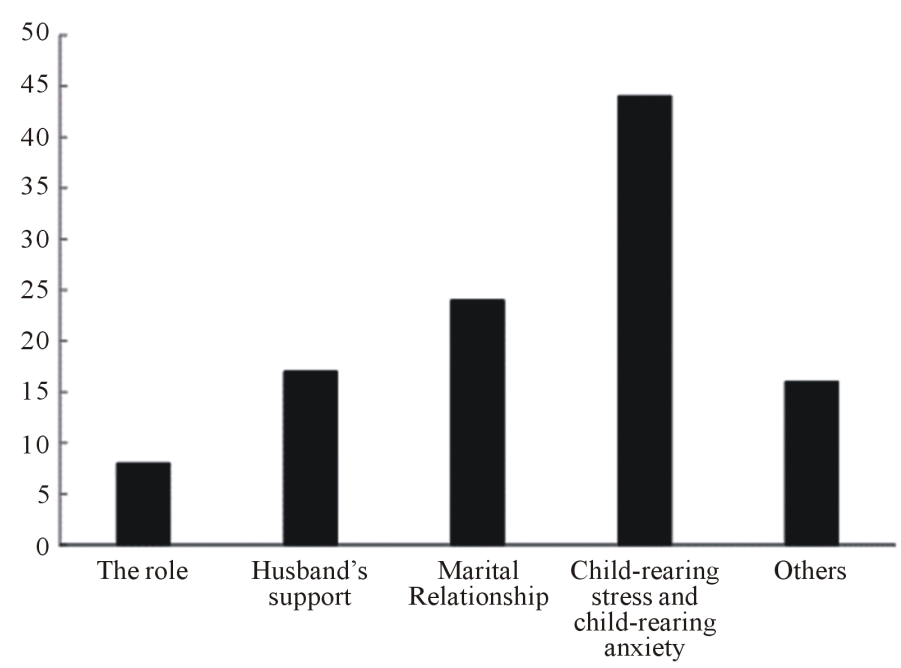

Figure 2. Classifying by the theme.

faces his child after the child gets birth. Kamiya and Kikuchi (2004) had a longitudinal study from before the child birth to after the child birth. They revealed that both husband's and wife's value of parental role changes at the point of child birth and that wife plays more parental role than husband after the child birth. Niwano (2008) also suggested so through her interview survey of the process to balance job-work and child-rearing. On the other hands, Kamiya (2006) revealed that husband also has an interest in child-rearing. Although husband doesn't have an identity of parenthood before child birth, he becomes to recognize the parental role when he aware of wife's hardiness of child-rearing after the child birth. Taga (2005) said though husband wants to participate in child rearing, he can't because of long time work to earn more money for supporting his family.

Couple has to play not only parental role but also other various roles to make a living with their children. There are roles according to works they have to carry such as household work, child-rearing work, or job-work and roles according to their standpoints such as partner, worker, or parent. Both husband and wife are required to play multiple roles. So they have the role conflict. Mitsui and Kita (2005) who focused on husband's role conflict revealed that the more husband plays household worker role, the stronger he makes an attachment with their children and the less role conflict he has. The role conflict of full-time working wife is stronger than that of house wife and full-time working wife has higher sense of guilt for not being able to be with her child during working time (Maruyama et al., 2002). Husband and wife need to distribute the roles to reduce burdens each other. Watanabe and Higai (2004) studied about the value of division of roles and revealed that it is important for couple's communication and the amount of role satisfaction to have the value that child-rearing work is a couple's collaborative work rather than to have same value of division of roles among couple. To have the value 
that child-rearing work is a couple's collaborative work increases the frequency of couple's communication and the amount of satisfaction with couple's communication is high. What's more, it decreases wife's child-rearing anxiety and increase husband's support.

As a result, survey shows although wife mainly plays a parental role, husband also wants to participate in child-rearing. But he can't because of his working time. And both wife and husband have the role conflict. It can be said having the value that child-rearing work is a couple's collaborative work is important for couple relationship.

2) Husband's support

These days husband's participation in child-rearing is interested. Many studies examine how husband cares his children, how he supports his wife, what the effective method of husband's child-rearing is.

Husband's participation in child rearing reduces wife's child-rearing anxiety, child-rearing stress, and feeling of child-rearing difficulty. And husband's mental support and couple's communication reduce wife's impulsive feeling and child-rearing anxiety (Matsumura, 2006). But Nakagawa (2010) insisted that wife's home role awareness increases wife's child-rearing behavior and household work, but those decrease husband's participation in child rearing. Kubo (2007) revealed that commuting and working time and easiness to take a paid leaves for child rearing influence husband's participation in child rearing. A study which examined relevance between wife's child-rearing stress and husband's participation in child-rearing evaluated by both husband and wife suggested that wife's child-rearing anxiety is decreased only when husband's household and child-rearing behavior is positively evaluated by his wife (Tanaka, 2010). From these studies it was revealed that although husband's support has an effect on decreasing wife's child-rearing anxiety, stress and impulsive feeling, husband is in the difficult situation to participate in child rearing because of wife's responsibility of housework and child rearing, working time, and difficulty to take paid leaves. What's more, husband's participation in child rearing doesn't have the effect unless wife evaluates it positively. To have the effect on decreasing wife's burden of child rearing husband has to consider how to participate in child rearing.

Watanabe and Higai (2004) examined effects of husband's child-rearing behavior and couple's communication. They revealed that the amount of wife's child-rearing satisfaction is high if couple communicates frequently. Kamiya and Kikuchi (2004) suggest that husband's supports which wife evaluates positively or which reduce wife's negative feeling are husband's mental support and couple's communication. Through these indirect supports of child rearing, husband can notice wife's difficulty of child rearing or can share value of child-rearing. Couple's communication bases on the interaction of the couple. So not only husband but also wife has to make an effort to communicate with her husband. Wife can gain more support from her husband if she has communication skills to tell her feelings or thoughts.

3) Marital relationship

There are many studies about changes of marital relationship in the child-rearing period. Lots of those use satisfaction scales of marital relationship which are adding evaluation index of marital relationship. The childrearing period has big impact on wife because she has to choice her life course. This choice becomes to have more influence to marital relationship. If wife choices her life course for family, satisfaction of marital relationship is high (Mori, 2012).

After marriage the satisfaction of marital relationship decreases according to time. Wife's satisfaction decreases more dramatically than husband's satisfaction does, especially at the point of child birth. Ito et al. (1998) revealed that wife's satisfaction with the relationship gets worse earlier than husband's satisfaction. Onodera (2005) examined marital relationship longitudinally from the pregnancy period. The study revealed that the marital relationship get worse 2 years after the child birth but it keeps stable after that point, that wife's frustrated feeling and husband's nonparticipation in child rearing affects decreasing of satisfaction of marital relationship, and that frustrated and unstable feeling becomes high if both husband and wife endure each other. Sagara et al. (2008) suggested satisfaction with marital relationship is maintained high if a difference between ideal and reality of sex role division of labor is small.

4) Child-rearing anxiety and child-rearing stress

Most of couples feel child-rearing stress because they have to do not only their own works but also childrearing work and can't stop worrying about child development. Although burden of child-rearing leads childrearing stress, wife who mainly cares the child feels child-rearing anxiety worrying about her ways of childrearing. Right after the child birth wife uses social support to cope with the stress (Nagata et al., 2011). Araki et al. (2001) revealed that wife needs the social support from her mother or her husband. 
Studies about child-rearing stress and child-rearing anxiety have focused only on wife. Recently it is revealed that husband also feels child-rearing stress. Husband feels difficulty in child rearing because he has a little time with his child and he doesn't know the way of child-rearing. Shimizu et al. (2008) suggested that husband who feels much child-rearing stress uses negative coping skills such as escaping from the situation. The negative coping skill makes the situation worse and husband feels more child-rearing stress. On the other hands husband who feels less child-rearing stress has more interest in his child and uses positive coping skill such as calling for social supports. Social support is effective not only for reducing wife's child-rearing stress but also for reducing husband's child-rearing stress. It is important not to hold child-rearing stress in him or her.

Hatsutsuka and Ishida (1996) focused on the difference of the ways to feel child-rearing stress between husband and wife. They revealed that the difference of wife's working styles is bigger than that between husband and wife. What is more, the pattern of feeling child-rearing stress of full-time working wife is tend to resemble to that of husband. The full-time working wife feels less domestic stress than housewife or part-time working wife. Yaegashi and Ogawa (2002) suggested that the incidents of child-rearing anxiety are different between a full-time working wife and a housewife. These results insisted the relevance between working styles and child-rearing stress or anxietaph within a graph is an "inset", not an "insert". The word alternatively is preferred to the word "alternately" (unless you really mean something that alternates).

\section{Discussion}

This study surveyed studies about couples in the child-rearing period and classified those studies into 4 main themes: 1) the role, 2) husband's support, 3) marital relationship, and 4) child-rearing anxiety and child-rearing stress. The result shows 1) though wife mainly plays parental role husband also wants to participate in child-rearing work. But his long working time and commuting time refuse him to do so. 2) The amount of husband's support depends on incidents of his wife and his social role and effective husband's support is mental support or couple's communication. 3) After the marriage marital relationship gets worse and wife's satisfaction of marital relationship decrease dramatically. But good marital relationship can maintain if wife choices her life course for her family and if difference between an ideal and a reality of role division of labor is small. 4) How to feel child-rearing stress depends on working styles. The child-rearing stress of full-time working wife is smaller than that of housewife and social support is effective to reduce child-rearing stress.

I'll discuss recent child-rearing for Japanese couples with these results and Japanese social backgrounds.

1) The role

Tendency that wife mainly carries child-rearing work is also seen in Europe and America (Belsky \& Pensky, 1988). It can be said that the tendency isn't a characteristic of Japanese couples but of couples in the child-rearing period. Wife is aware of parental role when she is in the pregnancy period. She experience big physical changes in the period but husband is gradually aware of parental role after the child birth when he experience hard time with his child like crying at night, exchanging diaper, and so on (Kono et al., 2001). These physically hard experiences make an opportunity to be aware of parental role. Difference of the time to be aware of parental role leads difference of the time to start child-rearing behavior as parents. Although wife who is aware of parental role earlier requires child-rearing behaviors of husband, husband can't response to the request because he isn't ready for being a parent. Adams (1965) proposed equity theory. It refers that people think as equal when demands and rewards are same rate. According to this theory it is supposed that wife starts to feel unequal to husband from early stage of child-rearing period. This seems one of the incidents to reduce wife's satisfaction of marital relationship.

There is a fact that husband also wants to participate in child rearing. Surveys of Cabinet Office (2013) revealed that the number of husbands who answered child rearing is couple's cooperative work is bigger than that of wives who answered so. This suggests that husbands rather than wives have an awareness of husband's participation in child rearing. Japanese traditional value of sex role division of labor may have changed little by little. On the other hands, the international comparing of the time of child-rearing shows the time of Japanese husbands is much shorter than that of other countries' husbands. These facts suggest that although the awareness has gradually changed, it hasn't linked with real child-rearing behavior yet. Kubo (2007) revealed that the amount of husband's participation in child rearing is related to commuting and working time. Considering these situations and facts, working environment which is good for couple's collaborative child-rearing hasn't been prepared yet in Japan. 
2) Husband's support

As this study has already showed husband's mental support and couple's communication reduce wife's child-rearing stress and child-rearing anxiety. In facts lots of husbands participate in child rearing play with child or give child a bath and don't care their wives (Cabinet Office, 2013). Wife requires supports not for the burden of child-rearing itself but mental burden which is arise from child-rearing. But husband only does substantial care for his child and doesn't care his wife. There is a gap between wife's demand and husband's reward. Tanaka (2010) suggested that wife's child-rearing stress decreases only the case wife evaluates husband's child-rearing behavior as good. Although husband participates in child rearing, it can be thought that the behavior doesn't reduce wife's child-rearing stress unless wife doesn't evaluate it positively. To maintain the relationship within the limited time couple may as well communicate each other and share wife's burden been arise from child rearing.

3) Marital relationship

Marital relationship gradually gets worse after the marriage. Especially in child-rearing period especially wife's satisfaction of marital relationship decreases dramatically. These aren't the characteristic of Japanese couples but the characteristic of couples in child-rearing period (Belsky \& Pensky, 1988). The child-rearing period seems to be the first period for couple to confront the crisis of the relationship. According to cognitive evaluation theory, a feeling toward a matter depends on evaluation of the matter. In the child-rearing period various gaps are likely to arise among couple and these gaps can bring negative feelings. These feelings lead to reduce satisfaction of marital relationship. Couple is needed thinking out to accept the gaps among couple as differences or not to arise the gaps to maintain good marital relationship.

Recently wife's decision of her life course is focused as a matter of affecting marital relationship (Mori, 2012; Kosaka et al., 2007). It may show that not only men but also women are focused as individuals, not only as mothers. It may be influenced by social progress of women which occurred following Europe and America. Lots of wives want to rework or continue working after their children birth. But more than half of them have to give up their hope because of economical reason, difficulty to balance between work and child-rearing, and so on (Cabinet Office, 2004). Bianchi (2004) insisted that in America the reduction of wife's child-rearing time for her work is covered by increasing the quality of child-rearing and it encourages husband participation in child-rearing. But in Japan husband has to work harder to earn more money after the child birth and his working time become longer. This makes it difficult for husband to participate in child rearing. Comparing with countries of Europe and America, the allowance for couples in the child-rearing period is low in Japan (Fukuda, 2003). It can be indicated that economical support for them isn't enough in Japan. Enhancement of systems or supports for easiness of childrearing is needed to maintain good marital relationship.

4) Child-rearing stress and child-rearing anxiety

There is no difference of the way of feeling child-rearing stress among couple. The effective coping method for child-rearing stress is common among couple. Difference about the way of feeling child-rearing stress comes from difference of working style. Working styles affects life styles, so the way to use time and the attitude toward childrearing differs according to the working styles. These are thought to affect the way of feeling childrearing stress. What is notable is though full-time working wife has less time for childrearing she feels less child-rearing stress than housewife does. These days the number of nuclear family is increased in Japan and this makes difficult situation for wives to have supports from their mothers. Housewife is in the difficult situation to receive social supports from both her mother and others outside of her family. But full-time working wife is easier to obtain supports from outside her family. What's more full-time working wife is easier to have pastime not being a mother. These situations may make difference between full-time working wife and housewife.

Although the number of double-earner couples is increasing, some couples can't be double-earner. One of the reasons is the issue of children on waiting lists. The time when a child enter a nursery school is one of the points starting to be a double-earner couple. But there aren't enough nursery schools in Japan. So husband or wife has to give up working. There isn't enough institutions to support double-earner couples in the child-rearing period in Japan. In current situation in Japan, more child care services are needed to support the couples.

\section{Conclusion}

This study aims to reveal the characteristics of Japanese couples in the child-rearing period through surveying the Japanese studies and to discuss the present situation and the future of them. Results show that wife mainly 
carries child-rearing work and husband also wants to participate in child-rearing work though he can't because of his working time. The way of feeling child-rearing stress and child-rearing anxiety is affected by working styles and that wife's child-rearing stress and child-rearing anxiety are reduced by mental support or couple's communication.

The facts that wife's satisfaction of marital relationship dramatically decreases in the child-rearing period and that wife mainly carries child-rearing work are also revealed in other countries' studies. So those may be common characteristics of the child-rearing period. On the other hands, little time of husband's participation in child-rearing and the issue of children on waiting lists are Japanese specific problems. This situation can be said that Japanese social systems for couples in the child-rearing period aren't enough. Social support for them is also needed to be enriched. To maintain good marital relationship in the current situation, couple should communicate a lot and share the idea of childrearing.

\section{Acknowledgements}

I want to express my gratitude to Kenji Kameguchi who gave me opportunity to submit. And he looked through whenever I revised the paper. Thank you very much.

\section{References}

Araki, M., Oishi, K., Iwaki, H., Watanabe, S., Ikeda, S. Tatsuda, S., \& Ogawa, Y. (2001). Association between Social Support to Mothers in the Nursing Stage and Stress. Bulletin of the School of Allied Medical Sciences, Nagasaki University, 14, 89-95.

Aramaki, M., \& Muto, T. (2008). Factors Related to Negative and Positive Feelings about Child-Rearing: A Survey of Mothers of Young Children. Japan Society of Developmental Psychology, 19, 87-97.

Belsky, J., \& Pensky, E. (1988). Marital Change across the Transition to Parenthood. Marriage and Family Review, 12, 133156. http://dx.doi.org/10.1300/J002v12n03_08

Cabinet Office (2004). Public Opinion Survey on a Gender-Equal Society. http://www.gender.go.jp/about_danjo/whitepaper/h16/gaiyou/html/honpen/chap01_03.html

Cabinet Office (2010). Public Opinion Survey on a Gender-Equal Society. http://www.gender.go.jp/about_danjo/whitepaper/h22/gaiyou/index.html

Cabinet Office (2013). Public Opinion Survey on a Gender-Equal Society. http://www.gender.go.jp/about danjo/whitepaper/h24/gaiyou/index.html

Fukuda, N. (2003). Comparing Family-Friendly Policies in Japan and Europe: Are We in the Same or in a Different League. Journal of Population and Social Security, 1, 31-45.

Hatsutsuka, M., \& Ishida, M. (1996). Mental Stress on Parents as a Result of their Child Rearing in Connection with the Mother's Employment Status. Bulletin of Osaka University, 45, 31-42.

Ito, N., Beppu, S., Miyamoto, S., \& Miyamoto, M. (1998). Stability and Change in Marriage across the Transition to Parenthood in Japan. Annual Report of the Faculty of Education, Gifu University. Humanities and Social Sciences, 47, $207-214$.

Kamiya, T. (2006). An Idiographic Approach to Change of Parental Role Concepts in Married Couples. Journal of Regional Sciences, 2, 367-388.

Kamiya, T., \& Kikuchi, T. (2004). Change of Parental Role Concepts in Married Couples. Journal of Japanese Association of Family Psychology, 18, 29-42.

Kosaka, C. (2007). The Attitude and Feelings of Childrearing in Full-Time Working Mothers of Young Children. Human Development Research, 19, 81-96.

Kubo, K. (2007). A Factor to Decide the Division of Child-Rearing Work of Full-Time Working Couple-Mainly about Child-Rearing Which Causes a Time Tangle of Work. Japan Society of Family Sociology, 19, 20-31. http://dx.doi.org/10.4234/jjoffamilysociology.19.2_20

Kuramochi, K., Tamura, T., Kubo, K., \& Oikawa, Y. (2007). Changes in Couple’s Attitude along the Child Development. Journal of the Japan Society of Home Economics, 58, 389-396.

Maruyama, N., Hamada, M., Ota, A., \& Takeuchi, S. (2002). Study about Role Tangle of Couple in Child-Rearing PeriodEspecially the Case of Full-Time Working Wife and Housewife. Japan Society of Research on Early Childhood Care and Education, 55, 854-855.

Matsumura, T. (2006). A Study of the Relation with Husband and Mother's Emotion in Child-Rearing Period (Impulsive Feeling and Child-Rearing Anxiety). Mie Nursing Journal, 6, 11-20. 
Mitsui (Nakaura), Y. \& Kita, J. (2005). Father’s Participation in Family Role and Its Predictors in the Early Child Care Period of the First Child. Bulletin of Faculty of Medical Health in Kobe University, 21, 63-77.

Mori, Y. (2012). Relation between Reason to Choice Woman's Life Course and Satisfaction with Marital Relationship. Studies of Japanese Association of Educational Psychology, 54, 143.

Motoyasu, K., \& Yaegashi, M. (2002). A Study on Relation between Mothers’ Anxiety to Raising Children and Working Situation. Journal of Kawasaki University of Medical Welfare, 12, 219-239.

Nagata, M., Nakamichi, Y., Noguchi, Y., \& Hirata, N. (2011). Childrearing Stress Coping Strategies in Mothers at 1 and 4 Months Postpartum: Positivity in Childrearing. Japan Society of Maternal Health, 54, 609-615.

Nakagama, H., Nozue, T., Nunoshiba, Y., \& Muto, K. (2008). Family Psychology: Development of Family System and Clinical Support. Tokyo: Yuikaku Books.

Nakagawa, M. (2010). Wives' Maternal Gatekeeping and Their Husbands' Involvement in Childcare and Housework with Children under 12 Years Old. Japan Society of Family Sociology, 22, 201-212. http://dx.doi.org/10.4234/jjoffamilysociology.22.201

Niwano, A. (2008). The Case Study about Interplay between Work and Family-A Tangle and Mutual Promotion Which Occur in a Process of Balancing the Two. PROCEEDINGS, 3, 35-46.

Onodera, A. (2005). Marital Changes during the Transition to Parenthood. Human Development Research, 16, 15-25.

Sagara, J., Ito, Y., \& Ikeda, M. (2008). Relationship between Marital Satisfaction of Married Couples, and Discrepancies between Ideals and Realities of Sharing of Housework and Child-Raising. Japanese Association of Family Psychology, 22, 119-128.

Sato, Y. (2013). Families of Preschoolers: Their Life and Psychology. Bulletin of Kamakura Women's University, 20, 1-10.

Shimizu, N., Sumioka, R., Kishihara, M., \& Manabe, E. (2008). Child-Rearing Fathers' Stressors, Stress-Responses and Stress-Copings during Childcare Period. Bulletin of Kyoto Prefectural University of Medicine, 17, 79-86.

Taga, F. (2005). Contradictions in the Gender Division of Labor and the Father’s Role. Kansai Sociological Review, 4, 4856.

Tanaka, K. (2010). Changes in Father's Behavior in Child Rearing and Housekeeping and Husband's Satisfaction of the Relationship between Husband and Wife and the Correlation with the 6-th Mother's Stress in Child Rearing. Annual Report of Faculty of Human culture, 25, 125-134.

Watanabe, T., \& Higai, S. (2004). Studies on a View on Share of Role and the Satisfaction of Role with Husband and Wife for Child-Care. Yamanashi Nursing Journal, 2, 37-44.

Yaegashi, M., \& Ogawa, T. (2002). A Study on Relation between Mothers’ Anxiety to Raising Children and Working Situations. Journal of Kawasaki Medical Welfare Society, 219-239. 